论 文

\title{
非弹性应变恢复法三维地应力测量一一汶川地震 科学钻孔中的应用
}

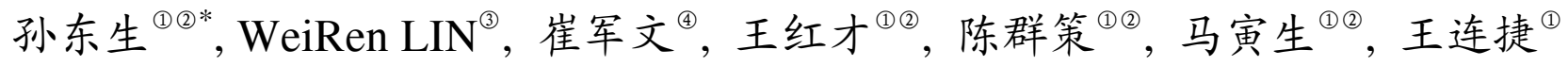 \\ (1) 中国地质科学院地质力学研究所, 北京 100081 ; \\ (2) 国土资源部新构造运动与地质灾害重点实验室, 北京 100081; \\ (3) Kochi Institute for Core Sample Research, Japan Agency for Marine-Earth Science and Technology (JAMSTEC), Nankoku 783-8502, Japan; \\ (4) 中国地质科学院地质研究所, 北京 100037 \\ *E-mail: dongshengsun@189.cn
}

收稿日期: 2013-04-09; 接受日期: 2013-07-26; 网络版发表日期: 2014-01-16

国家科技支撑-汶川地震断裂带科学钻探井中探测项目(编号：2008WFSD-03)、国土资源部深部探测技术与试验研究专项(编号: SinoProbe-07)、日本学术振兴会基金项目(编号: B-25287134)和中国地质科学基本科研业务费(编号: SYS1301)资助

\begin{abstract}
摘要＼cjkstart随着地球动力学和深部能源开发利用等研究工作的不断深入, 深部应力状态 的研究越来越重要, 但目前尚没有即经济又简便完善的深部三维地应力测量方法. 基于 岩芯的非弹性应变恢复法是近年来发展起来的深部三维应力测量方法. 汶川 $5 \cdot 12$ 地震 后, 中国大陆首次将该方法应用于科学钻孔的地应力测量. 本文详细介绍了这一方法现 场测量岩芯非弹性恢复应变的基本流程, 并对此法测量的岩芯首次开展了岩石非弹性 应变恢复柔量的实验研究, 将现场非弹性应变测量与室内非弹性应变恢复柔量实验相 结合, 确定汶川地震科学钻一号孔(WFSD-1) $1173 \mathrm{~m}$ 处最大主应力方向为 $\mathrm{NW} 64^{\circ}$, 实测 得到岩石的剪切与体积模式非弹性应变恢复柔量的比值为 2.9 , 计算得到最大、中间和最 小主应力分别为 43,28 和 $25 \mathrm{MPa}$. 结合龙门山地区其他方法的地应力测量结果, 表明龙 门山断裂带从 NE 到 SW 现今最大主应力作用方向表现为由 $\mathrm{EW} \rightarrow \mathrm{NEE} \rightarrow \mathrm{NWW}$ 的变化 规律, 龙门山断裂带现今地应力作用方向的分段性特征与 $5 \cdot 12$ 汶川地震时龙门山断裂 带西南段逆冲为主, 东北段走滑为主的运动特点相吻合, 研究结果对于认识汶川地震的 动力学机制具有一定参考价值.
\end{abstract}

关键词

汶川 $M_{\mathrm{s}} 8.0$ 地震 岩芯非弹性应变恢复 非弹性应变恢复柔量 三维地应力

科学钻孔
为更好理解大地震的孕育机理、动力学过程、地 表破裂及地震周期特征等过程, 已经开展了大量针 对大地震机理研究的科学研究和钻探计划(马宗晋和 蒋铭, 1987; 张国民, 1987; Bohnhoff 等, 2004; Hickman 和 Zoback, 2004; Wu 等, 2007; Yamashita 等, 2004;
Stein, 1999; Hardebeck, 2004; Lin 等, 2007; Chester 等, 2012; Wolter 和 Berckhemer, 1989; Hung 等, 2009). 地 应力作为诱发地震的直接驱动力之一, 是以地震机 理研究为目的科学钻探计划的主要研究对象. 开展 地震前后及地震周期内断裂带附近的应力变化规律

中文引用格式: 孙东生, Lin W R, 崔军文, 等. 2014. 非弹性应变恢复法三维地应力测量——汶川地震科学钻孔中的应用. 中国科学: 地球科学, 44: 510-518 英文引用格式: Sun D S, Lin W R, Cui J W, et al. 2013. Three-dimensional in situ stress determination by anelastic strain recovery and its application at the Wenchuan Earthquake Fault Scientific Drilling Hole-1 (WFSD-1). Science China: Earth Sciences, doi: 10.1007/s11430-013-4739-6 
的研究对地震发生的机理及分布规律研究具有重要 的意义(王连捷等, 2012; Lin 等, 2011; 石耀霖和曹建 玲, 2010; 张贝和石耀霖, 2010; 陈颙, 2009; Brown 和 Hoek, 1978; Chang 等, 2010; Sun 等, 2013). 存在于地 壳岩体内的应力场可通过多种直接或间接的方法测 量(Zang 和 Stephansson, 2010), 但截至目前还没有一 种既经济又有效的方法可以测量深部三维原地应力 的大小和方向(Dey 和 Kranz, 1988). 对于深钻孔而言, 目前常用的地应力测量方法主要包括水压致裂法、钻 孔崩落法和钻井诱发裂缝等.

基于岩芯的非(滞)弹性应变恢复法(Anelastic strain recovery method, 简称 ASR 法) 是近年来发展起来的 基于定向岩芯的深孔地应力测量方法. 与其他岩芯 法地应力测量相比, ASR 法具有较完善的理论基础, 该方法最早由 Voight(1968)提出, 认为岩石具有流变 性, 应力释放后岩石的非弹性恢复应变与原地应力 状态相关. 作为二维地应力测量方法, ASR 法在油气 田地应力测量工作中得到了广泛应用(Voight, 1968; Engelder, 1984; Warpinski 和 Teufel, 1989; Perreau 等, 1989). ASR 法与其他原地应力测量方法相比具有成 本低、效率高且不受钻孔深度和温度的限制, 可进行 三维应力测量等优点, 只要能够获取定向岩芯, 就可 进行 ASR 法的测量, 确定主应力的方向. 该方法的 缺点是非直接测量, 需要实验确定岩石的非弹性应 变恢复柔量才能够计算地应力大小. 汶川地震科学 钻一号孔(WFSD-1)地应力测量的初始方案是开展包 括 ASR 法在内的多种方法联合测量, 并对不同方法 的结果进行比较, 提高结果的可信性. 但由于 WFSD-1 钻孔岩芯较破碎, 应用解除法和水压致裂等 方法存在一定困难, 故只开展了 ASR 法地应力测量. 实际上, 进行地应力测量时, 最好使用多种方法(最 少两种)进行, 并对不同方法的结果进行比较, 以提 高结果的可信性(Warpinski 和 Teufel, 1989; Perreau 等, 1989).

Matsuki(1991)从理论上将 ASR 法发展为三维地 应力测量方法, 并在以地震、构造活动等科学研究中 得到广泛应用(Matsuki 和 Takeuchi, 1993; Lin 等, 2006, 2007a; Byrne 等, 2009). ASR 法的测量原理和方 法方面, 前人做了详细的工作 (王连捷等, 2012; Matsuki, 1991; Matsuki 和 Takeuchi, 1993; Lin 等, 2006, 2007b; Byrne 等, 2009; 林为人, 2008), 但在确 定地应力大小时, 是依据垂向应力等于上覆岩层的
重力和剪切与体积模式柔量的比值等于 2 的假设进行 (王连捷等, 2012; 林为人, 2008; Brereton 等, 1995). 本文结合 WFSD-1 钻孔 $1173 \mathrm{~m}$ 岩芯的非弹性应变测 量, 并对同一岩芯开展了非弹性应变恢复柔量实验, 根据非弹性应变恢复柔量的实验结果确定了 WFSD-1 钻孔 $1173 \mathrm{~m}$ 的地应力大小, 结合其他方法 得到的测量结果分析了龙门山断裂带浅部的最大主 应力方向变化规律, 最后对 ASR 法地应力测量的影 响因素进行了讨论.

\section{ASR 法地应力测量的基本原理及本构方程}

\subsection{ASR 法的基本原理}

钻孔中的岩芯被钻取后, 即脱离应力场的作用, 岩芯除了立即发生弹性应变恢复以外, 还随时间发 生非弹性(滞弹性)应变恢复, 其原理基于岩石是一种 黏弹性体, 具有流变性(耶格和库克, 1981; 尹祥础, 1985; 陈颙, 1988). 岩石的流变模式如图 1 所示, 当 对岩石施加载荷时, 立即产生弹性变形, 然后产生暂 态蠕变; 当载荷卸去时, 弹性恢复瞬间完成, 进而发 生非弹性恢复. Voight(1968)根据经验, 提出非弹性 恢复应变正比于总恢复应变(包括弹性和非弹性应 变), 进而提出对于各向同性具有流变特性的岩石, 可通过测量岩芯卸荷后的非弹性恢复应变确定原地 应力的方向，估算原地应力的大小.

\subsection{ASR 法的本构方程}

岩石卸荷后的非弹性应变 $\varepsilon_{\mathrm{a}}(t)$ 与原地应力之间 的关系如式(1)(Lin 等, 2006):

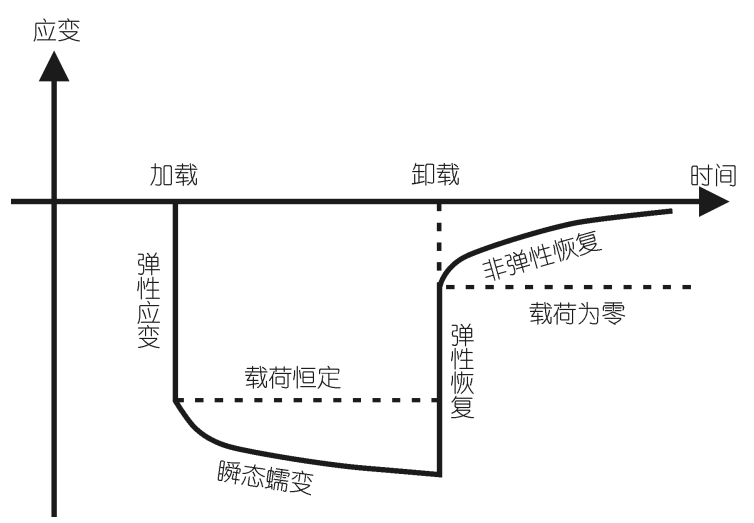

图 1 岩石流变性的模式图(王连捷等, 2012) 


$$
\begin{aligned}
\varepsilon_{a}(t)= & \frac{1}{3}\left[\begin{array}{l}
\left(3 l^{2}-1\right) \sigma_{x}+\left(3 m^{2}-1\right) \sigma_{y}+\left(3 n^{2}-1\right) \sigma_{z} \\
+6 \operatorname{lm} \tau_{x y}+6 m n \tau_{y z}+6 n l \tau_{z x}
\end{array}\right] \\
& \times \operatorname{Jas}(t)+\left(\sigma_{m}-p_{0}\right) \operatorname{Jav}(t)+\alpha_{T} \Delta T(t) .
\end{aligned}
$$

式中, $l, m, n$ 为应变轴的方向余弦, $\sigma_{x}, \sigma_{y}, \sigma_{z}, \tau_{x y}, \tau_{y z}, \tau_{z x}$ 为应力张量分量, $\sigma_{m}$ 为平均正应力, $p_{0}$ 为孔隙压力, $\alpha_{T}$ 为线性热膨胀系数, $\Delta T(t)$ 为测量期间温度变化, $\operatorname{Jas}(t)$ 和 $\operatorname{Jav}(t)$ 分别为剪切和体积变形模式的非弹性应变恢 复柔量. 对于三维主应力的大小, 可通过式(2)表示:

$$
\sigma_{i}=e_{i}(t) / \operatorname{Jas}(t)+\left\{e_{m}(t)-\sigma_{T} \Delta T(t)\right\} / \operatorname{Jav}(t)+p_{0}, i=1,2,3,
$$

式中, $e_{i}(t)$ 为非弹性偏应变, $e_{m}(t)$ 为平均正应变.

从式(1)可以看出, 非弹性应变与原地应力分量、 测量期间的温度变化、热膨胀系数、孔隙压力和非弹 性应变恢复柔量有关. 因此, 在测量期间如果孔隙压 力、温度不发生变化的情况下, 应力分量可通过测量 不少于 6 个独立方向非弹性正应变及岩石的非弹性应 变恢复柔量确定. 对于各向同性的黏弹性岩石而言, 主应力方向与主应变张量的方向一致, 因此只需确 定主应变的方向. 图 2 为 ASR 法确定三维地应力状 态的技术流程.

\section{2 现场非弹性恢复应变测量}

现场岩芯非弹性应变恢复测量在 WFSD-1 钻孔 现场实验室进行. WFSD-1 钻孔位于四川省都江堰市 虹口镇 $\left(31.149^{\circ} \mathrm{N}, 103.691^{\circ} \mathrm{E}\right)(\mathrm{Li}$ 等, 2012), 距 $5 \cdot 12$ 地 震震中约 $90 \mathrm{~km}$. 与地表主断裂的水平距离约 $400 \mathrm{~m}$. 钻井总深度 $1201 \mathrm{~m}$, 井斜为 $13.5^{\circ}$, 垂深约 $1168 \mathrm{~m}$. 地表至孔深 $176 \mathrm{~m}$ 为震旦系下统的变质火山岩, 176 $589.2 \mathrm{~m}$ 为新元古代彭灌杂岩, 589.2 1201 $\mathrm{m}$ 为三叠 系上统须家河组, 主要为砂岩、砾岩、泥岩和页岩煤 系地层. 孔深 $590 \mathrm{~m}$ 附近出现厚达 $70 \mathrm{~cm}$ 的断层泥, 被认为是汶川地震的滑移断层 ( $\mathrm{Li}$ 等, 2012; 彭华等, 2011). 为缩短应力释放到开始测量的时间间隔, 岩 芯应尽量选取某一回次下部、无明显裂缝且各向同性 (肉眼观察)的岩芯, 岩芯长度以 10 15 $\mathrm{cm}$ 为宜. 带有 定向标志线的岩芯经清洗后, 沿基线 ( $x^{\prime}$ 轴)以及与基 线相隔 $45^{\circ}, 90^{\circ}$ 和 $-45^{\circ}$ (顺时针方向为负)线粘贴应变 片, 即 $\mathrm{C} 1, \mathrm{C} 2, \cdots, \mathrm{C} 18$ (共 18 个应变计), 应变片的布置 如图 3 所示. 粘贴好应变片的样品用锡簿袋包裹并用 硅橡胶密封袋口, 以消除孔隙水的蒸发, 封装好的样

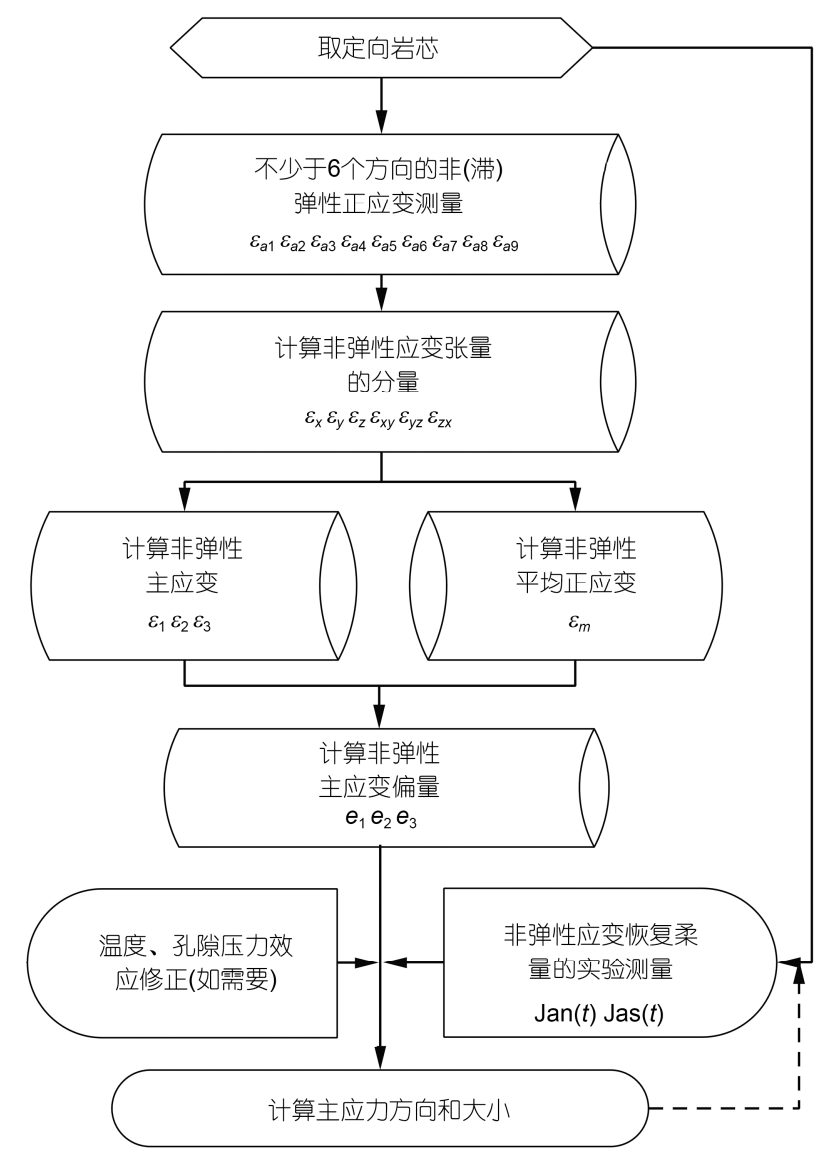

图 2 ASR 法确定三维应力状态的流程(Matsuki 和 Takeuchi, 1993)

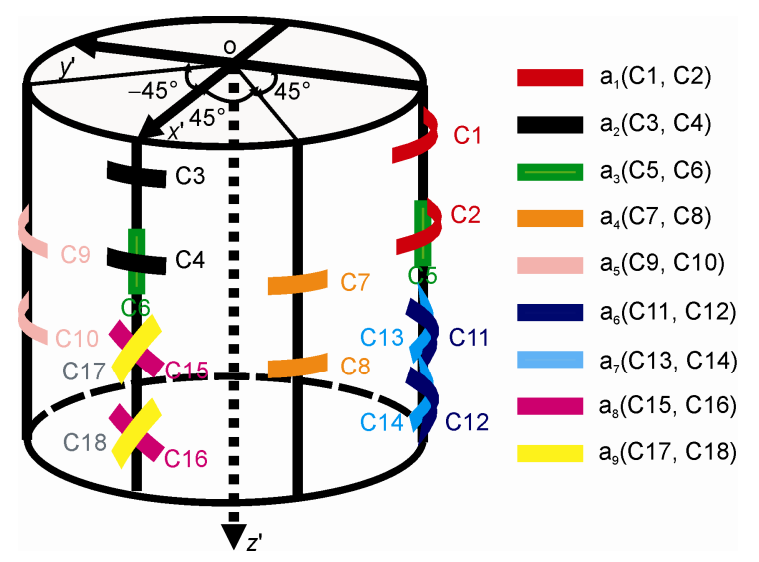

图 3 岩芯表面应变计的布置

品放入具有恒温控制的水槽中, 并尽可能快的开始 测量(从岩芯被钻取到开始 ASR 测量的时间一般不超 过 $5 \mathrm{~h}$, 且越快越好)。测量中采用三线制电阻应变片 和精密数据记录仪记录应变和温度变化. 测量过程中 
用贴有同样应变片的致密砂岩样品监测数据的漂移.

本文测量样品取自 WFSD-1 孔 $1173 \mathrm{~m}$ 处的三叠 系须家河组长石砂岩, 测量期间采用水浴恒温控制, 温度变化小于 $\pm 0.1^{\circ} \mathrm{C}$, 测量得到的岩芯非弹性应变恢 复曲线如图 4(a). 测量结果显示, 测量系统的温度影 响可忽略. 各个应变计的非弹性应变皆为正应变, 曲 线随时间平稳增加, 初期非弹性应变增加较快, 然后 变缓, 符合非弹性应变变化规律. 通过测量岩芯卸荷 后的非弹性应变, 计算得到非弹性主应变和平均应 变(图 4(b)), 具体的数据处理及坐标转换方法参阅文 献(王连捷等, 2012).

\section{3 岩石非弹性应变恢复柔量的实验确定}

非弹性应变恢复柔量是岩石的固有力学属性, 是 ASR 法地应力测量中, 将现场测得的非弹性应变 观测值换算成为原地应力大小的一个重要参数, 他 的物理意义为单位应力引起的非弹性应变随时间变 化的函数(Matsuki 和 Takeuchi, 1993).

室内实验测定岩石非弹性应变恢复柔量的基本 流程如下: 首先对岩芯样品进行加载并保持(载荷持 续时间 $24 \mathrm{~h}$ 以上), 然后快速卸载. 通过记录加载、加 载保持、卸载和卸载后恢复过程中岩样的轴向和径向 应变(包括弹性和非弹性应变). Matsuki(2008)对包括 砂岩、凝灰岩和花岗岩在内的 7 块岩石进行了单轴条 件下的非弹性应变恢复实验(载荷为 $50 \%$ 单轴抗压强 度), 确定岩石的剪切和体积模式非弹性应变恢复柔

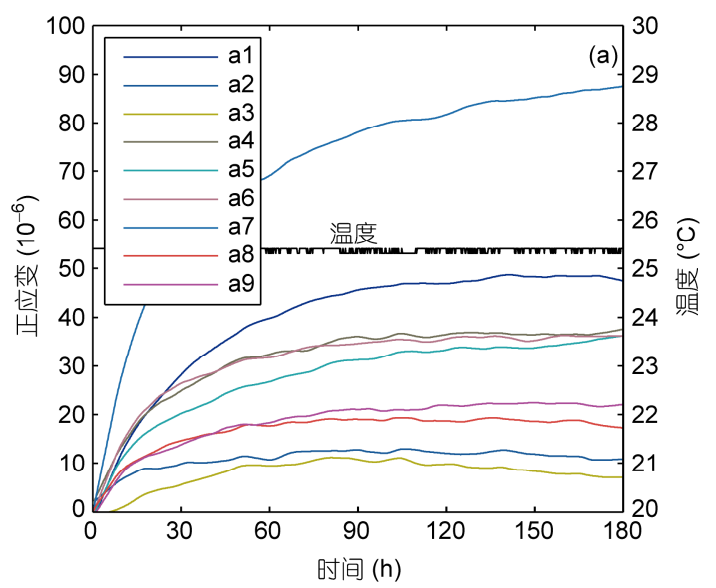

量 $\operatorname{Jas}(t)$ 与 $\operatorname{Jav}(t)$ 的比值范围是 1 3. 本文对汶川地震 科学钻孔 $1173 \mathrm{~m}$ 深处的三叠系长石砂岩, 进行了单 轴条件下的非弹性应变恢复实验. 首先对岩芯施加恒 定的单轴载荷(70 MPa, 50\%单轴抗压强度), 加载过 程如图 5(a), $70 \mathrm{~h}$ 后, 快速卸载使载荷为零. 加载、暂 态蠕变、卸载和非弹性恢复过程的轴向和径向应变曲 线如图 5(b), 去除弹性应变后的暂态蠕变和非弹性应 变恢复过程曲线如图 5(c).

根据实验得到岩石卸荷后的非弹性恢复应变, 利用式(3)计算得到样品的非弹性应变恢复柔量 $\operatorname{Jas}(t)$, $\operatorname{Jav}(t)$ 和比值 $\operatorname{Jas}(t) / \operatorname{Jav}(t)$. 计算结果如图 6. 结果表明 非弹性应变恢复柔量 $\operatorname{Jas}(t)$ 和 $\operatorname{Jav}(t)$ 随时间的增加而 增加, 且增加的速率逐渐变慢. 二者的比值 $\operatorname{Jas}(t) / \operatorname{Jav}(t)$ 在约 $10 \mathrm{~h}$ 后基本保持不变.

$$
\operatorname{Jav}(t)=\frac{\varepsilon_{1 a}+2 \varepsilon_{3 a}}{\sigma_{1}+2 \sigma_{3}}, \operatorname{Jas}(t)=\frac{\varepsilon_{1 a}-\varepsilon_{3 a}}{\sigma_{1}-\sigma_{3}} .
$$

为简化 ASR 法中确定岩石非弹性应变恢复柔量 的方法, Matsuki 等(1993)指出不同应力环境下岩石的 剪切与体积模式非弹性应变恢复柔量的比值趋于定 值. 因此在确定 $\operatorname{Jas}(t) / \operatorname{Jav}(t)$ 的比值及假设垂向应力 等于上覆岩层重力的条件下, 即 $\sigma_{v}=\rho g h$. 可通过(4) 式确定非弹性应变恢复柔量 $\operatorname{Jas}(t)$ 和 $\operatorname{Jav}(t)$, 然后由式 (2)求出主应力 $\sigma_{i}(i=1,2,3)$.

$$
\sigma_{v}=\left\{\left[l_{p}^{2} e_{1}(t)+m_{p}^{2} e_{2}(t)+n_{p}^{2} e_{3}(t)\right] / K+e_{m}(t)\right\} / \operatorname{Jav}(t)+p_{0},
$$

式中, $l_{p}, m_{p}$ 和 $n_{p}$ 为铅直应力与 3 个应变主轴之间的方

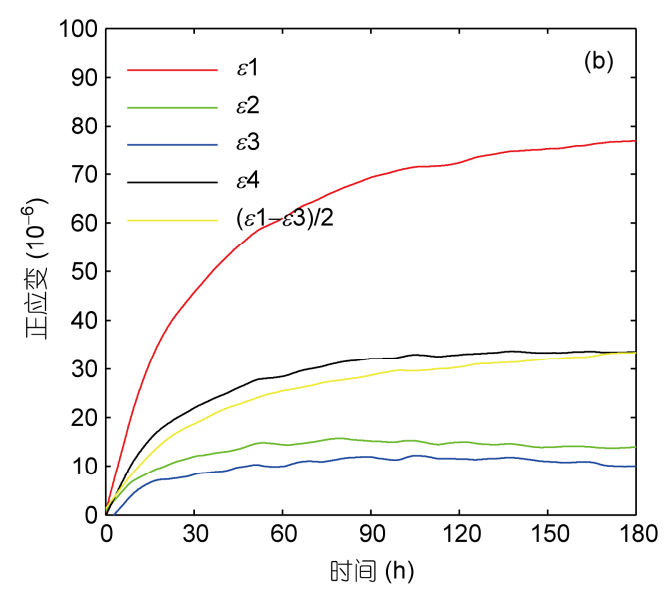

图 4 非弹性恢复应变随时间变化曲线

(a) 不同方向的非弹性恢复应变; (b) 非弹性主应变、平均应变和最大差应变 

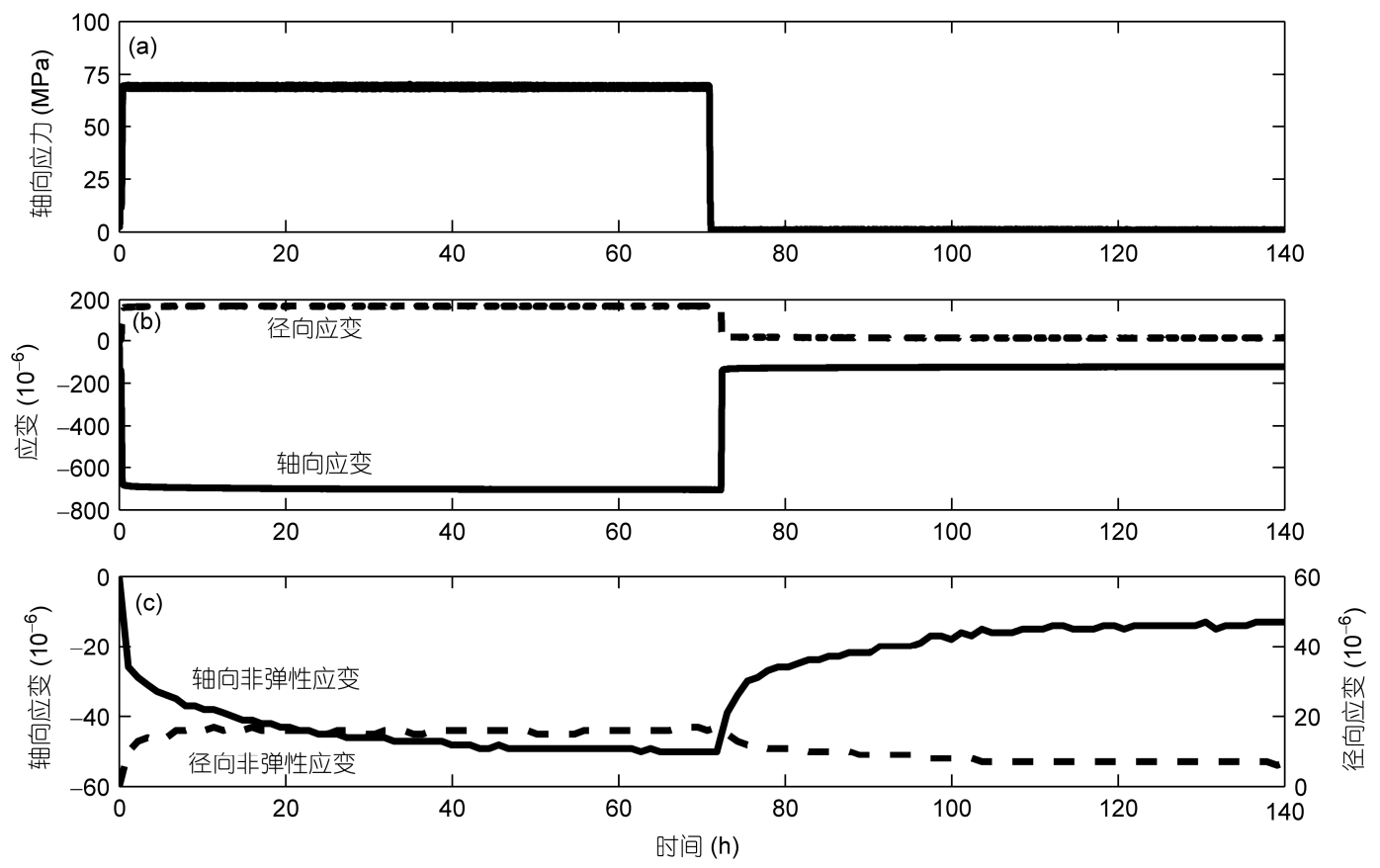

图 5 实验确定岩石非弹性应变恢复柔量

(a) 为轴向加载和卸载过程; (b) 为加载过程的弹性变形、暂态蠕变、卸载弹性变形和非弹性恢复应变曲线; (c) 为暂态蠕变和非弹性恢复过 程的应变曲线. 实线为轴向应变; 虚线为径向应变

向余弦, $K$ 为 $\operatorname{Jas}(t) / \operatorname{Jav}(t)$ 的比值.

\section{WFSD-1 钻孔地应力测量结果及龙门山} 断裂带附近最大主应力方向

\section{1 原地应力测量结果}

由 9 个方向的应变观测曲线, 在进行岩芯坐标轴 的方位及井斜的校正后, 使用最小二乘法并计算得 到主应变的方位和倾角(王连捷等, 2012). 如前所述, 在均匀各向同性介质中, 主应变的方位即为主应力 的方位. 假定铅直应力等于上覆岩层的重量(岩层的 平均密度为 $2.71 \mathrm{~g} \mathrm{~cm}^{-3}$ ), 实验确定岩芯的非弹性应 变恢复柔量的比值 $\operatorname{Jas}(t) / \mathrm{Jav}(t)=2.9$, 则用前述方法, 计算得出 3 个主应力的大小分别为 43,28 和 $25 \mathrm{MPa}$. WFSD-1 钻孔 $1173 \mathrm{~m}$ 处原地应力测量结果如表 1 所示.

\section{2 龙门山断裂带应力状态分析}

通过 ASR 法得到 WFSD-1 钻孔 $746 \mathrm{~m}$ (王连捷等, 2012)和 $1173 \mathrm{~m}$ 处为逆断层的应力状态, 最大水平主 应力的方位分别为 $\mathrm{NW} 49^{\circ}$ 和 $\mathrm{NW} 64^{\circ}$, 与 $5 \cdot 12$ 汶川大 地震时的断层滑动性质一致. 将 ASR 法得到的主

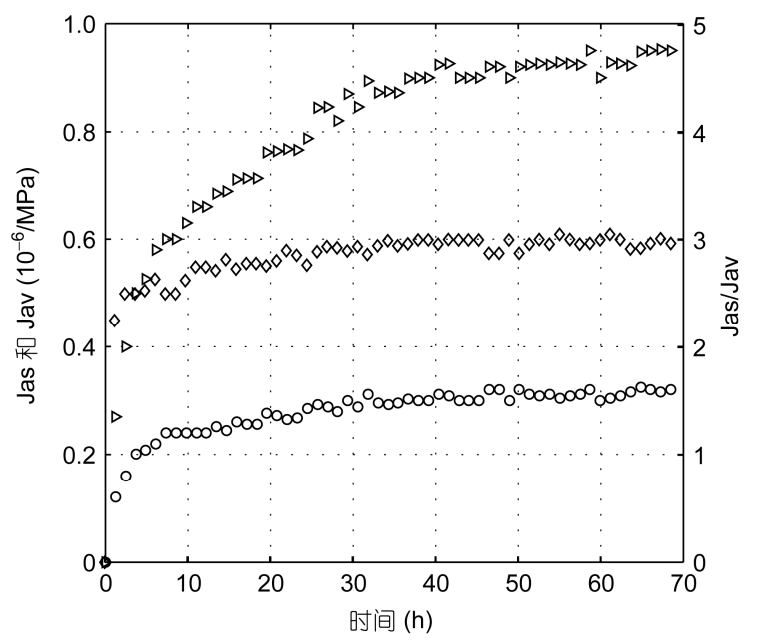

图 6 非弹性应变恢复柔量及其比值

应力方位(方向和倾角)与汶川 $M_{s} 8.0$ 地震震源机制解 $\mathrm{P}$ 轴方位画到赤平投影图上(图7(d), 下半球投影). 从 图上可以看出 ASR 法得到的最大主应力方位与震源 机制解的 P 轴方位基本一致(胡幸平等, 2008; 郑勇等, 2009; 崔效锋等, 2011).

结合汶川地震前后，通过钻孔水压致裂和地质 构造分析等方法, 得到龙门山断裂带多个测点的最 
表 1 主应力大小及方向

\begin{tabular}{|c|c|c|c|c|c|c|c|c|c|c|}
\hline \multirow{2}{*}{ 测点深度(m) } & \multirow{2}{*}{ 测点岩性 } & \multicolumn{3}{|c|}{$\sigma_{1}$} & \multicolumn{3}{|c|}{$\sigma_{2}$} & \multicolumn{3}{|c|}{$\sigma_{3}$} \\
\hline & & 大小 $(\mathrm{MPa})$ & 方位 & 倾角 & 大小 $(\mathrm{MPa})$ & 方位 & 倾角 & 大小 $(\mathrm{MPa})$ & 方位 & 倾角 \\
\hline 1173 & 三叠系长石砂岩 & 43 & $296^{\circ}$ & $26^{\circ}$ & 28 & $188^{\circ}$ & $33^{\circ}$ & 25 & $56^{\circ}$ & $46^{\circ}$ \\
\hline
\end{tabular}

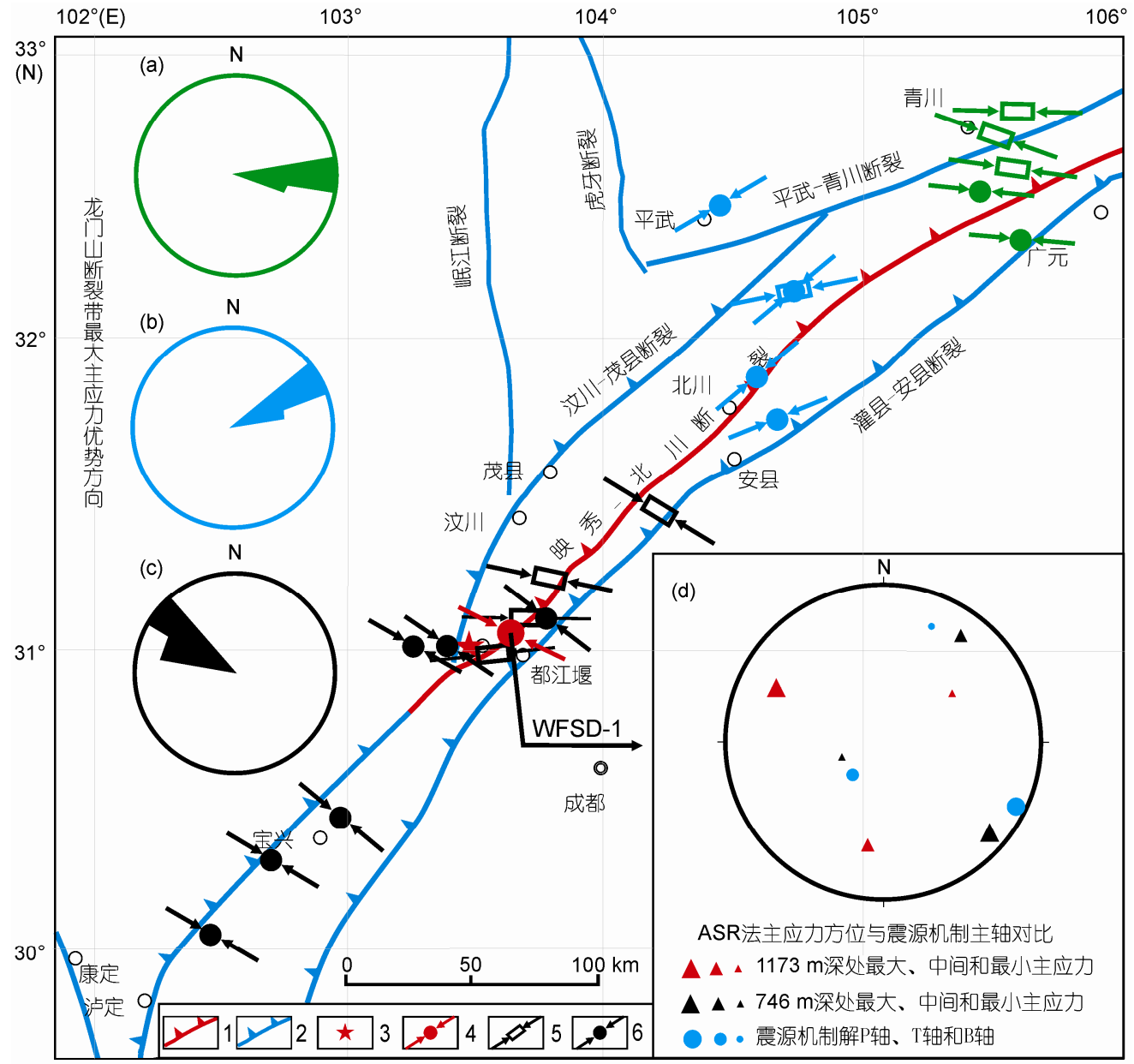

图 7 龙门山断裂带最大主应力方向及 WFSD-1 孔 ASR 法原地应力测量结果

(a) 广元青川附近最大主应力的优势方向; (b) 龙门山断裂带东北段最大水平主应力优势方向; (c) 龙门山断裂带西南段最大水平主应力优势 方向; (d) WFSD-1 钻孔 ASR 法测量得到最大主应力方位与震源机制解对比. 1,5 12 发震断层; 2, 断层; 3, 5 12 地震震中和震源机制解 P 轴 方向(胡幸平等, 2008; 郑勇等, 2009; 崔效锋等, 2011); 4, WFSD-1 的位置和 ASR 法得到的最大主应力方向; 5, 断层擦痕法得到的最大水平主 应力方向(谢富仁等, 2004; 杜义等, 2009; 刘健等, 2012); 6, 水压致裂法得到的最大水平主应力方向(陈群策等, 2012; Wu 等, 2009; 安其美等, 2004; 丰成君等, 2013)

大主应力方位(陈群策等, 2012; Wu 等, 2009; 安其美 等, 2004; 丰成君等, 2013; 谢富仁等, 2004; 杜义等, 2009; 刘健等, 2012), 经统计得到龙门山断裂带现今 地应力作用方向的分段性特征(陈群策等, 2012). 广 元青川附近最大主应力的优势方向为为 NWW 或近 东西方向(图 7(a)), 龙门山断裂带东北段北川、江油
和平武附近的最大水平主应力优势方向为 NEE 向(图 7(b)), 以北川为界的龙门山断裂带西南段的最大水 平主应力优势方向为 $\mathrm{NW}$ 向(图 7(c)), 反映了龙门山 断裂带由 $\mathrm{NE}$ 到 SW 段最大主应力方向由 $\mathrm{EW} \rightarrow \mathrm{NEE} \rightarrow$ NWW 的变化规律, 该认识与龙门山断裂带西南段逆 冲为主，东北段走滑为主的运动特点相吻合. 


\section{5 非弹性应变恢复柔量对原地应力大小的 影响}

除了通过实验确定岩石的剪切和体积模式的非 弹性应变恢复柔量外, 也可通过假设剪切与体积模 式非弹性应变恢复柔量的比值为定值和垂向应力为 上覆岩层重力, 计算岩石的非弹性应变恢复柔量. 根 据本文及 Matsuki(2008)的实验结果, 通常情况下由 于岩性和应力环境等的影响, 岩石的非弹性应变恢 复柔量的比值 $\operatorname{Jas}(t) / \operatorname{Jav}(t)$ 在 $1 \sim 3$. 为研究 $\operatorname{Jas}(t) / \operatorname{Jav}(t)$ 比值与主应力大小计算结果之间的联系, 本文给出 了所测样品的主应力与 $\operatorname{Jas}(t) / \operatorname{Jav}(t)$ 之间的关系曲线 如图 8, 从图上可以看出随着 $\operatorname{Jas}(t) / \mathrm{Jav}(t)$ 比值的增加, 主应力的计算结果逐渐减小. 如果假设 $\operatorname{Jas}(t) / \mathrm{Jav}(t)=$ 2 , 而实验结果其比值为 2.9 , 估算引起最大、中间和 最小主应力的误差分别为 $5.7 \%, 4.6 \%$ 和 $4.4 \%$. 而对 于一些测试结果, 随着剪切柔量与体积柔量比值的 增加, 最大主应力减小, 而中间和最小主应力增加 (Lin 等, 2006). 目前, 对于岩石非弹性恢复柔量的实 验研究数据较少, 以后应加强常见岩石的柔量实验 工作, 在获得大量的柔量数据基础上, 对柔量的分布 进行概率分析, 进而对 ASR 的测量误差进行评价.

\section{6 讨论}

\section{1 时间因素的影响}

岩芯脱离应力场作用后, 弹性应变瞬间恢复, 非 弹性应变亦立即开始恢复, 但岩芯由钻孔深处提取 到地面及实验前的预处理等需要一定时间, 因而测 量不能立即开始, 而是滞后一段时间, 导致一部分初 始恢复量损失. 同时, 岩芯卸荷后的非弹性恢复速率 随着时间的增加而降低, 非弹性恢复应变将随着测 量时间的延迟而快速减小. 从理论上讲, 只要获取部 分非弹性恢复应变, 即可确定原地应力状态. 但对测 量误差而言, 只有岩芯钻取后尽快开始测量以获取 最大化的非弹性恢复应变, 才能尽可能消除误差对 测试结果的影响.

\section{2 温度变化对结果的影响}

岩石的非弹性应变恢复测量过程中, 温度是影 响测量结果的一个重要因素, 测量过程中温度变化 引起的热应变是不可忽略的. 对于热属性为各向同

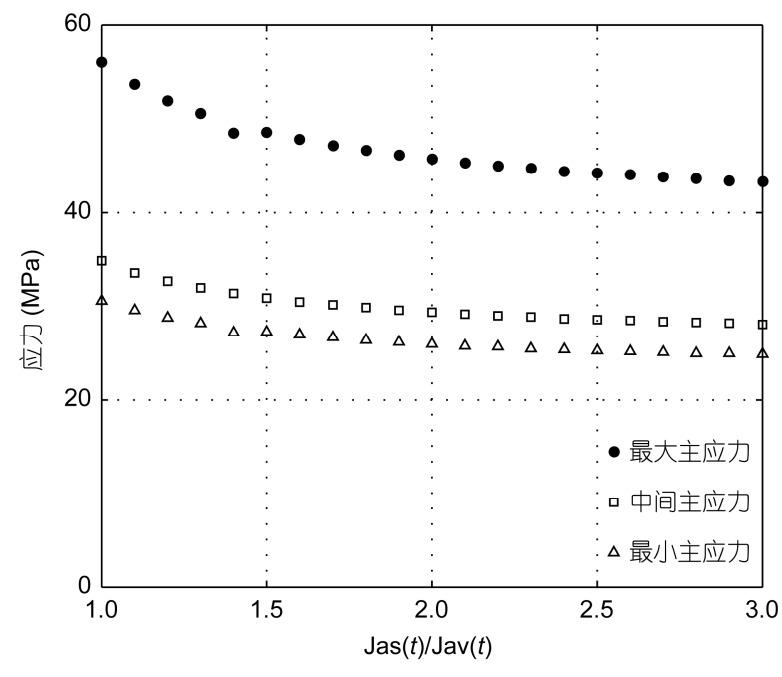

图 8 主应力大小与非弹性应变恢复柔量比值的关系

性的岩石而言, 温度变化仅对平均应变有影响, 对偏 应变无影响. 正如前面提到的, 主应力的方向与主应 变偏量的方向一致, 因此温度变化对主应力的方向 无影响, 但由于主应力大小与非弹性恢复应变的绝 对值及非弹性应变恢复柔量有关, 故温度变化对主 应力的大小有影响. 本文采用恒温水浴循环器控制 水槽中水的温度, 其温度波动小于 $\pm 0.1^{\circ} \mathrm{C}$, 同时应变 片采用三线制，消除了温度对导线电阻的影响. 但在 实验室进行岩石非弹性应变恢复柔量实验中, 由于 实验室不具有恒温环境, 只能通过空调系统消除昼 夜温差, 其保持恒温效果相对较差. 同时, 实验中采 用相同的样品作为温度补偿样品, 以消除温度变化 所带来的误差.

\section{3 其他影响因素分析}

ASR 法是以均质且各向同性介质的假设为前提 的. 为保证测量结果的可靠性, 一般通过目视来选择 均质且各向同性的岩芯.为保持岩芯试样的原位状态, 测量期间岩芯用锡纸袋密封，保持含水率不变. 同时 ASR 法地应力测量比较适用于深孔岩芯, 因为深度越 大, 应力越大, 非弹性应变恢复量也越大, 这样可以尽 量消除测量误差对结果的影响. 岩石的强度对非弹性 恢复应变也有一定影响, 对于坚硬岩石的非弹性应变 测量, 深度较大时更适用(Zang 和 Stephansson, 2010).

\section{7 结论}

本文将 ASR 法应用于 WFSD-1 钻孔的地应力测 
量, 得到了 WFSD-1 钻孔 $1173 \mathrm{~m}$ 深处岩芯的三维非 弹性恢复应变, 并对同一岩芯开展了岩石的非弹性 应变恢复柔量实验, 得到了对应岩芯的非弹性应变 恢复柔量, 给出 WFSD-1 钻孔 $1173 \mathrm{~m}$ 深处主应力的 大小分别为 43,28 和 $25 \mathrm{MPa}$. 测试结果与其他方法 得到的原地应力结果基本吻合.

结合龙门山断裂带其他测量方法的原地应力测 量结果表明: 沿龙门山断裂带从 NE 到 SW, 现今最 大主应力作用方向表现为由 $\mathrm{EW} \rightarrow \mathrm{NEE} \rightarrow \mathrm{NWW}$ 的变 化规律, 龙门山断裂带现今地应力作用方向的分段
性特征与 $5 \cdot 12$ 汶川地震时龙门山断裂带西南段逆冲 为主，东北段走滑为主的运动特点相吻合.

非弹性应变恢复柔量对 ASR 法确定地应力大小 的影响分析表明: 将现场非弹性恢复应变测量与室 内非弹性应变恢复柔量实验结合起来, 可提高 ASR 法 确定地应力大小的精度, 使非弹性应变恢复法具有更 大的实用价值. 特别在较大深度的钻孔和地层较破碎 的复杂地质条件下, 应力解除法, 水压致裂法等难以 实施时, 此方法仍有可能获得较可靠的地应力数据, 且不受测量深度和温度的限制, 具有更广泛的适用性.

\section{参考文献}

安其美, 丁立丰, 王海忠, 等. 2004. 龙门山断裂带的性质与活动性研究. 大地测量与地球动力学, 24: 115-119

陈群策, 丰成君, 孟文, 等. 2012.5 12 汶川地震后龙门山断裂带东北段现今地应力测量结果分析. 地球物理学报, 55: 3923-3932

陈颙. 2009. 汶川地震是由水库蓄水引起的吗? 中国科学 D 辑: 地球科学, 39: 257-259

陈颗. 1988. 地壳岩石的力学性能一理论基础与实验方法. 北京: 地震出版社. 1-279

崔效锋, 胡幸平, 余春泉, 等. 2011. 汶川地震序列震源机制解研究. 北京大学学报(自然科学版), 47: 1063-1072

杜义, 谢富仁, 张效亮, 等. 2009. 汶川 $M_{\mathrm{s}} 8.0$ 级地震断层滑动机制研究. 地球物理学报, 52: 464-473

丰成君, 陈群策, 谭成轩, 等. 2013. 汶川 $M_{\mathrm{s}} 8.0$ 地震对龙门山断裂带附近地应力环境影响初探一以北川、江油地区为例. 地震学报, 35 : 137-150

胡幸平, 俞春泉, 陶开, 等. 2008. 利用 $\mathrm{P}$ 波初动资料求解汶川地震及其强余震震源机制解. 地球物理学报, 51: 1711-1718

林为人. 2008. 基于岩芯非弹性应变恢复量测定的深孔三维地应力测试方法. 岩石力学与工程学报, 27: 2387-2394

刘健, 熊探宇, 赵越, 等. 2012. 龙门山活动断裂带运动学特征及其构造意义. 吉林大学学报(地球科学版), 42(增刊): 320-330

马宗晋, 蒋铭. 1987. 中国的强震期和强震幕. 中国地震, 3: 47-51

彭华, 马秀敏, 姜景捷. 2011. 差应变法地应力测量一以汶川地震断裂带科学钻探 WFSD-1 钻孔为例. 地质力学学报, 17: 249-261

石耀霖, 曹建玲. 2010. 库仑应力计算及应用过程中若干问题的讨论一以汶川地震为例. 地球物理学报, 53: 102-110

王连捷, 孙东生, 林为人, 等. 2012. 地应力测量的非弹性应变恢复法及应用实例. 地球物理学报, 55: 1674-1681

尹祥础. 1985. 固体力学. 北京: 地震出版社. 1-512

谢富仁, 崔效锋, 赵建涛, 等. 2004. 中国大陆及邻区现代构造应力场分区. 地球物理学报, 47: 654-662

耶格 J C, 库克 N G W. 1981. 岩石力学基础. 中国科学院工程力学研究所(译). 北京: 地震出版社. 382-397

张国民. 1987. 我国大陆强震活动的韵律性特征. 地震地质, 9: 27-38

张贝, 石耀霖. 2010. 紫坪铺水库对附近断层稳定性影响的探讨. 中国科学院研究生院报, 27: 755-762

郑勇, 马宏省, 吕坚, 等. 2009. 汶川地震强余震 $\left(M_{\mathrm{s}} \geqslant 5.6\right)$ 的震源机制解及其与发震构造的关系. 中国科学 D 辑: 地球科学, 39: 413-426

Bohnhoff M, Baisch S, HarjesH P. 2004. Fault mechanisms of induced seismicity at the super deep German Continental Deep Drilling Program

(KTB) borehole and their relation to fault structure and stress field. J Geophy Res, 109: B02309, doi: 10.1029/2003JB002528

Brereton N R, Chroston P N, Evans C J. 1995. Pore pressure as an explanation of complex anelastic strain recovery results. Rock Mech Rock Eng, 28: 59-66

Brown E T, Hoek E. 1978. Trends in relationships between measured rock in situ stresses and depth. Int J Rock Mech Min Sci, 15: 211-215

Byrne T B, Lin W, Tsutsumi A, et al. 2009. Anelastic strain recovery reveals extension across SW Japan subduction zone. Geophys Res Lett, 36 : L23310, doi: 10.1029/2009GL040749

Chang C, McNeill L C, Moore J C, et al. 2010. In situ stress state in the Nankai accretionary wedge estimated from borehole wall failures. Geochem Geophys Geosyst, 11: Q0AD04, doi: 10.1029/2010GC003261

Chester F M, Mori J J, Toczko S, et al. 2012. Japan Trench Fast Drilling Project (JFAST). IODP Prel Rept, 343/343T, doi: 10.2204/iodp. pr.343343T.2012

Dey T N, Kranz R L. 1988. State of stress and relationship of mechanical properties to hydrothermal alteration at Valles Caldera Core Hole 1,

New Mexico. J Geophy Res, 93: 6108-6112 
Engelder T. 1984. The time-dependent strain relaxation of Algerie granite. Int J Rock Mech Min Sci, 21: 63-73

Hardebeck J L. 2004. Stress triggering and earthquake probability estimates. J Geophys Res, 109: B04310, doi: 10.1029/2003JB002437

Hickman S, Zoback M. 2004. Stress orientations and magnitudes in the SAFOD pilot hole. Geophy Res Lett, 31: L15S12, doi: 10.1029/ 2004GL020043

Hung J H, Ma K F, Wang C Y, et al. 2009. Subsurface structure, physical properties, fault zone characteristics and stress state in the scientific drill holes of Taiwan Chelungpu Fault Drilling Project. Tectonophysics, 466: 307-321

Li H, Wang H, Xu Z, et al. 2012. Characteristics of the fault-related rocks, fault zones and the principal slip zone in the Wenchuan Earthquake Fault Scientific Drilling Project Hole-1 (WFSD-1). Tectonophysics, 584: 23-42

Lin W, Kwasniewski M, Imamura T, et al. 2006. Determination of three-dimensional in situ stresses from anelastic strain recovery measurement of cores at great depth. Tectonophysics, 426: 221-238

Lin W, Yeh E, Ito H, et al. 2007a. Preliminary results of stress measurement by using drill cores of TCDP Hole-A: An application of anelastic strain recovery method to three-dimensional in situ stress determination. Ter Atmos Ocea Sci, 18: 379-393

Lin W, Yeh E C, Ito H, et al. 2007b. Current stress state and principal stress rotations in the vicinity of the Chelungpu fault induced by the 1999 Chi-Chi, Taiwan, Earthquake. Geophys Res Lett, 34: L16307, doi: 10.1029/2007GL030515

Lin W, Doan M L, Moore J C, et al. 2010. Present-day principal horizontal stress orientations in the Kumano forearc basin of the southwest Japan subduction zone determined from IODP NanTroSEIZE drilling Site C0009. Geophys Res Lett, 37: L13303, doi: 10.1029/2010GL043158

Lin W, Saito S, Yamamoto Y, et al. 2011. Principal horizontal stress orientations prior to the $2011 M_{\mathrm{w}} 9.0$ Tohoku-Oki, Japan, earthquake in its source area. Geophy Res Lett, 38: L00G10, doi: 10.1029/2011GL049097

Matsuki K. 1991. Three-dimensional in situ stress measurement with anelastic strain recovery of a rock core. In: Wittke W, ed. Proc 7th Int Congr Rock Mech. Aachen. 557-560

Matsuki K, Takeuchi K. 1993. Three-dimensional in situ stress determination by anelastic strain recovery of a rock core. Int J Rock Mech Min Sci, 30: $1019-1022$

Matsuki K. 2008. Anelastic strain recovery compliance of rocks and its application to in situ stress measurement. Int J Rock Mech Min Sci, 45: 952-965

Perreau P J, Heugas O, Santarelli F J. 1989. Tests of ASR, DSCA, and core discing analyses to evaluate in situ stresses. SPE paper 17960, SPE Middle East Oil Technical Conference and Exhibition Manama, Bahrain. 325-336

Stein R S. 1999. The role of stress transfer in earthquake occurrence. Nature, 402: 605-609

Sun D S, Wang L J, Wang H C, et al. 2013. Analysis of the Wenchuan $M_{\mathrm{s}} 8.0$ Earthquake Co-seismic stress and displacement change by using the finite element method. Acta Geol Sin, 87: 1120-1128

Voight B. 1968. Determination of the virgin state of stress in the vicinity of a borehole from measurements of a partial anelastic strain tensor in drill cores. Felsmechanik und Ingenieurgeologie, 6: 201-215

Wu H Y, Ma K F, Zoback M, et al. 2007. Stress orientations of Taiwan Chelungpu-Fault Drilling Project (TCDP) hole-A as observed from geophysical logs. Geophy Res Lett, 34: L01303, doi: 10.1029/2006GL028050

Wolter K E, Berckhemer H. 1989. Time dependent strain recovery of cores from the KTB-Deep drill hole. Rock Mech Rock Eng, 22: 273-287

Warpinski N R, Teufel L W. 1989. In situ stresses in low permeability, nonmarine rocks. J Petrol Technol, 41: 405-414

Wu M L, Zhang Y Q, Liao C T, et al. 2009. Preliminary results of In-situ stress measurements along the Longmenshan Fault Zone after the Wenchuan $M_{\mathrm{s}} 8.0$ Eratherquare. ACTA Geol Sin, 83: 746-753

Yamashita F, Fukuyama E, Omura K. 2004. Estimation of fault strength: Reconstruction of stress before the 1995 Kobe earthquake. Science, 306 : 261-263

Zang A, Stephansson O. 2010. Stress Field of the Earth's Crust. London: Springer. 115-193 